\title{
Network on Chip for 3D Mesh Structure with Enhanced Security Algorithm in HDL Environment
}

\author{
Adesh Kumar \\ Assistant Professor, Department \\ of Electronics Engineering, \\ University of Petroleum \& \\ Energy Studies, Dehradun, \\ India
}

\author{
Sonal Singhal, PhD. \\ Assistant Professor, Department \\ of Electrical Engineering, Shiv \\ Nadar University, Gautam \\ Buddh Nagar, NCR, India
}

\author{
Piyush Kuchhal, PhD. \\ Associate Professor \& Head, \\ Department of Physics, \\ University of Petroleum \& \\ Energy Studies, Dehradun, \\ India
}

\begin{abstract}
Network on chip (NOC) architecture is an approach to develop large and complex systems on a single chip. In this work 3D mesh topological structures has been implemented with enhanced TACIT Security in HDL environment. The architecture supports physical and architectural level design integration. Basic communication mechanism between resources is envisioned to be packet switched message passing through the switches. For the node identification in 3D networks $8 \times 8 \times 8$ Mesh configuration is taken. A new Algorithm is proposed for secured data transmission among nodes. TACIT algorithm is used for data encryption and decryption and applicable for $\mathrm{n}$ bit block size and key. Design is implemented in Xilinx 14.2 VHDL software, and functional simulation was carried out in Modelsim $10.1 \mathrm{~b}$, student edition. Hardware parameters such as size cost and timings are extracted from the design code.

\section{General Terms}

TACIT Security, Simulation, Synthesis, Integrated Circuits, Intellectual Property

\section{Keywords}

Very High Speed Integrated Circuit hardware Description language (VHDL), Network on chip (NOC), System on chip (SOC)
\end{abstract}

\section{INTRODUCTION}

Today, many integrated circuits contain several processor cores, memories, hardware cores and analog components on the same chip [3]. Such Systems on Chip (SoC) are widely used in high volume and high-end applications, such as multimedia, aerospace and defense, wired and wireless communication systems. With the scaling in IC technology more and more processors are integrating on a single die and formed a multiprocessor system on chip (MPSoC). It results in the increase in the power consumption and wire delay [22]. In addition to this, with increased number of transistors and the die size, length of the interconnects also increases. With reducing geometries, the wire pitch and cross section also reduces, thereby increasing the RC delay of the wires [22]. This coupled with increasing interconnect length leads to long timing delays on global wires. Another major impact of increased lengths and RC values is that the power consumption of global interconnects become significant, thereby posing a big challenge for system designers. Current on-chip interconnects [18] consist of low-cost shared communication resources, where arbitration logic is needed for the serialization of bus access requests: only one master at a time can drive the bus. Major drawback of this solution is its lack of scalability, which will result in unacceptable performance degradation (e.g, contention-related delays for bus accesses) when the level of SOC integration will exceed a dozen of cores. Moreover, the connection of new blocks to a shared bus increases its associated load capacitance, resulting in more energy consuming bus transactions. Such factors make the on-chip communication among cores difficult. Therefore a scalable, energy-efficient on-chip interconnect network is needed to address these difficulties in order to expedite the on-chip communication [3].

Networked systems, such as the Internet, communication networks, World Wide Web, social networks, power grids, and many other networks [2] are complex systems. Networked systems exhibiting diverse phenomena such as spontaneous organization in network node states (coherence), discontinuous state transitions, and hysteresis .This Phenomena depends on its properties, such as the topology defining the neighbor relations, Network-on-Chip (NoC) is a developing model for communications within large VLSI systems implemented on a single silicon chip [21]. Sgroi et al. have defined the NoC methodology as the design of the on-chip inter-core communications by making use of the layered-stack approach [11]. In a NOC system, modules such as processor cores, memories and IP blocks exchange data using a network as a "public transportation" sub-system for the information traffic.

A NOC is constructed from multiple point-to-point data links interconnected by switches. NOC utilizes the circuit-switching techniques. Connection is made in such a way that messages can be relayed from any source module to any destination module over several links, by making routing decisions at the switches. These kinds of systems are used in the telephone exchanges, mobile communication, and topological networks where fast data transfer is required in the real time environment. From the communication perspective, there have been various topologies for NOC architecture, which include mesh, torus, ring, butterfly, octagon and irregular interconnection networks [5, 6]. Various researchers have exploited these different NOC topologies for their NOC implementations. Kim et al. have used a star-based NOC for communication using the principle of CDMA (Code Division Multiple Access) [7], Pande et al. compared various network topologies for interconnection networks in terms of latency, throughput, and energy dissipation [6]. Adriahantenaina et al. proposed a tree-based implementation of NOC [8], where each node in the tree behaves as a router in NOC several researchers have suggested that 2-D mesh architecture for NOC will be more efficient in terms of latency, power consumption and ease of implementation, as compared to other topologies. The Octagon NOC demonstrated in [9] is an example of a novel regular NOC topology. NOC architectures are based on packet-switched networks. This has led to new and efficient 
principles for design of routers for NOC [10]. Routing protocol for Mesh Topological Structure is implemented, Different Switching techniques, such as circuit switching, packet switching is implemented. NOC architecture [10][25] follows the bus based architecture, bus implementation is done for NOC, and for example AMBA bus for ARM Processor, Peripheral Controller interface (PCI) bus which connects the hardware to PC.

This work carries out the implementation of the chip for 3D $8 \times 8 \times 8$ Mesh Topological structures with secured data transmission among nodes. It employs the cross bar structure. Traffic can be diverted to any node by their address. Time division multiplexing techniques is used to detect the node which is applicable in telecommunication switching.

Tools Utilized: Design and implementation includes the ISE Design Suit 14.2, Xilinx software. It is used to design the IC and to view their RTL (Register Transfer Logic) schematic. ModelSim EE 10.1b students edition, Mentor Graphics is used for simulation and debugging the functionality. The chip implementation is done using VHDL programming language.

The paper is organized as follows: Section I presents the introduction and the tools utilized. Section II discusses the TACIT Security Algorithm. Section III presents the 3D mesh network. Section IV describes the Result and Performance Evaluation. Conclusion is presented in Section V.

\section{TACIT SECURITY ALGORITHM}

There are many encryption and decryption algorithms which are already proposed. A comparison [2] of all is shown in table 1 listed below. Table 1 list the comparison of various encryption algorithms on the basis of Type and Features. It can be seen that from this comparison table that TACIT Encryption Technique has a unique independent approach by using some suitable mathematical logic along with a new key distribution system which is being applied on a secure policy based routing [8]. The main advantage of TACIT logic is that it can processes n-bit blocks and n- bit key size. This approach may be good if the block size is less than the key size [2] [23]. The algorithm may be implemented in all the languages support Unicode system facility like Java, C\#, .Net, etc.

Table 1 Comparison of various encryption algorithms [21] on the basis of Key size and Block size.

\begin{tabular}{|l|l|l|l|}
\hline Algorithm & $\begin{array}{l}\text { Key } \\
\text { size(Bits) }\end{array}$ & $\begin{array}{l}\text { Block } \\
\text { size(Bits) }\end{array}$ & Features \\
\hline DES & 64 & 64 & $\begin{array}{l}\text { Most common, Not } \\
\text { strong enough }\end{array}$ \\
\hline $\begin{array}{l}\text { Triple } \\
\text { DES }\end{array}$ & 192 & 64 & $\begin{array}{l}\text { Modification of DES, } \\
\text { Adequate security }\end{array}$ \\
\hline AES & $\begin{array}{l}\text { Variable } \\
(192 \\
256)\end{array}$ & 128 & $\begin{array}{l}\text { Replacement of DES, } \\
\text { Excellent security, } \\
\text { limited key size }\end{array}$ \\
\hline $\begin{array}{l}\text { Kasumi } \\
\text { core }\end{array}$ & 128 & 64 & $\begin{array}{l}\text { Designed for Third } \\
\text { Generation } \\
\text { Partnership } \\
\text { Project(3GPP) used } \\
\text { in Universal Mobile } \\
\text { Telecommunication } \\
\text { System UMTS, } \\
\text { limited to 64-bit word } \\
\text { size }\end{array}$ \\
\hline Blowfish & 448 & 64 & $\begin{array}{l}\text { Excellent security, } \\
\text { No. of bits are } \\
\text { variable ranging from } \\
16-448 \text { bits. }\end{array}$ \\
\hline
\end{tabular}

\begin{tabular}{|l|l|l|l|}
\hline RSA & 1024 & 128 & $\begin{array}{l}\text { Asymmetric } \\
\text { algorithm, speed is } \\
\text { low }\end{array}$ \\
\hline RC4 & $\begin{array}{l}\text { Variable(4 } \\
0 \text { or 128) }\end{array}$ & $\begin{array}{l}\text { Variable } \\
(32,64,12 \\
8)\end{array}$ & $\begin{array}{l}\text { Fast stream chipper in } \\
\text { Secured Socket Layer } \\
\text { (SSL) more memory } \\
\text { is required since they } \\
\text { work on large chunk } \\
\text { of data (stream) } \\
\text { instead of block } \\
\text { cipher. }\end{array}$ \\
\hline $\begin{array}{l}\text { X- } \\
\text { MODES }\end{array}$ & 32 & 32 & $\begin{array}{l}\text { Enhanced security } \\
\text { level \& faster. }\end{array}$ \\
\hline $\begin{array}{l}\text { TACIT } \\
\text { Encryption }\end{array}$ & $\begin{array}{l}\text { n-bit } \\
\text { (ncan vary) }\end{array}$ & n-bit & $\begin{array}{l}\text { Good for small size } \\
\text { of packets }\end{array}$ \\
\hline
\end{tabular}

\subsection{Data Encryption Logic for TACIT Algorithm}

To implement the TACIT Logic [2] [23] for data communication between two nodes of NOC the following algorithm has been used. The corresponding VHDL coding has been developed and results are presented in section IV.

Step 1: Text file content is read and position of the character is shuffled by using initial permutation approach using key value. Step 2: Read the character from the text file corresponding to the text and get the ASCII value of that character.

Step 3: Perform XOR operation with the specific n-bit key value.

Step 4: A secure tacit logic has been introduced (i.e. $\mathrm{n}^{\mathrm{k}}$ xor $\mathrm{k}^{\mathrm{k}}$ along with some specific operations; where $n$ is the value computed from step 3).

Step 5: Convert the value into binary one.

Step 6: Perform reverse operation on the binary string.

Step 7: Corresponding decimal value is found.

Step 8: The Unicode character corresponds to the decimal value is formed which is none other than the cipher text.

Step 9: Continue step 1 to 7 for the next characters of the file until End of File (EOF) is reached.

\subsection{Data Decryption Logic for TACIT Algorithm}

The decryption algorithm [23] at the receiving end follows the following steps. In the decryption logic user can share the same key.

Step 1: Read the first character from the cipher text and get the corresponding decimal value of it.

Step 2: The corresponding binary value is evaluated and make the reverse of it.

Step 3: Inverse of the tacit logic is applied.

Step 4: Perform XOR with n-bit key value.

Step 5: The character corresponds to it is determined.

Step 6: Now reshuffling is done using key value.

Step 7: Repeat the steps (1 to 6) till the end.

\section{3D MESH NETWORK}

To understand the behavior of 3D NOC structure, understanding of $2 \mathrm{D}$ NOC structure is required. 2D NOC follows the cross point technology which allows addressing any node at any time [11]. A cross point switch is a switch connecting multiple inputs to multiple outputs in a matrix form. The 2D NOC architecture is a $\mathrm{m} \times \mathrm{n}$ mesh of switches [9] [10] and resources are placed on the slots formed by the switches. For an $\mathrm{m} \mathrm{x} \mathrm{n}$ architecture there are $\mathrm{m}$ nodes on $\mathrm{X}$ axis and $\mathrm{n}$ nodes on $\mathrm{Y}$ axis respectively. For the design and implementation of switching network, $8 \times 8$ architecture is 
considered in this work. With $8 \times 8$ switching mesh network 64 nodes can be addressed at one time. And to address the 64 nodes 3 bits were required individually for both the axes $\left(2^{\mathrm{n}}=\right.$ 8). 3 bits row address is assigned to nodes on $X$ axis. Similarly 3 bit address is assigned on the nodes on $\mathrm{Y}$ axis. Addressing and node selection scheme is described in the functional table (Table 2). It is evident from Table 2 that if the row address is 000 and column address is 110 , node $\mathrm{N}_{6}$ is selected; similarly any node could be selected based on node address table having row address and column address. Figure 1 shows the cross point structure and the node locations on the $\mathrm{X}$ and $\mathrm{Y}$ axis.

\begin{tabular}{|c|c|c|c|c|c|c|c|c|}
\hline & \multicolumn{8}{|c|}{ Column Address } \\
\hline Row & 000 & 001 & 010 & 011 & 100 & 101 & 110 & 111 \\
\hline Address & & & & & & & & \\
\hline 000 & $\mathrm{~N}_{1}$ & $\mathrm{~N}_{2}$ & $\mathrm{~N}_{3}$ & $\mathrm{~N}_{4}$ & $N_{5}$ & $\mathrm{~N}_{6}$ & $\mathrm{~N}_{7}$ & $\mathrm{~N}_{8}$ \\
\hline 001 & $\mathrm{~N}_{9}$ & $\mathrm{~N}_{10}$ & $\mathrm{~N}_{11}$ & $\mathrm{~N}_{12}$ & $\mathrm{~N}_{13}$ & $\mathrm{~N}_{14}$ & $\mathrm{~N}_{15}$ & $\mathrm{~N}_{16}$ \\
\hline 010 & $\mathrm{~N}_{17}$ & $\mathrm{~N}_{18}$ & $\mathrm{~N}_{19}$ & $\mathrm{~N}_{20}$ & $\mathrm{~N}_{21}$ & $\mathrm{~N}_{22}$ & $\mathrm{~N}_{23}$ & $\mathrm{~N}_{24}$ \\
\hline 011 & $\mathrm{~N}_{25}$ & $\mathrm{~N}_{26}$ & $\mathrm{~N}_{27}$ & $\mathrm{~N}_{28}$ & $\mathrm{~N}_{29}$ & $\mathrm{~N}_{30}$ & $\mathrm{~N}_{31}$ & $\mathrm{~N}_{32}$ \\
\hline 100 & $\mathrm{~N}_{33}$ & $\mathrm{~N}_{34}$ & $\mathrm{~N}_{35}$ & $\mathrm{~N}_{36}$ & $\mathrm{~N}_{37}$ & $\mathrm{~N}_{38}$ & $\mathrm{~N}_{39}$ & $\mathrm{~N}_{40}$ \\
\hline 101 & $\mathrm{~N}_{4}$ & $\mathrm{~N}_{4}$ & $\mathrm{~N}_{43}$ & $\mathrm{~N}_{44}$ & $\mathrm{~N}_{45}$ & $\mathrm{~N}_{46}$ & $\mathrm{~N}_{47}$ & $\mathrm{~N}_{48}$ \\
\hline 110 & $\mathrm{~N}_{49}$ & $\mathrm{~N}_{50}$ & $\mathrm{~N}_{51}$ & $\mathrm{~N}_{52}$ & $\mathrm{~N}_{53}$ & $\mathrm{~N}_{54}$ & $\mathrm{~N}_{55}$ & $\mathrm{~N}_{56}$ \\
\hline 111 & $N_{57}$ & $\mathrm{~N}_{58}$ & $\mathrm{~N}_{59}$ & $\mathrm{~N}_{60}$ & $\mathrm{~N}_{61}$ & $\mathrm{~N}_{62}$ & $\mathrm{~N}_{63}$ & $\mathrm{~N}_{64}$ \\
\hline
\end{tabular}

Figure 1, 2D Network structure ( 8 x 8$)$

Table 2 Node address generation scheme in 2D structure

\begin{tabular}{|c|c|c|}
\hline Row Address & Column Address & Destination Node \\
\hline 000 & 000 & Node 1 \\
\hline 000 & 001 & Node 2 \\
\hline 000 & 010 & Node 3 \\
\hline 000 & 011 & Node 4 \\
\hline 000 & 100 & Node 5 \\
\hline 000 & 101 & Node 6 \\
\hline 000 & 110 & Node 7 \\
\hline 000 & 111 & Node 8 \\
\hline 001 & 000 & Node 9 \\
\hline 001 & 001 & Node 10 \\
\hline 001 & 010 & Node 11 \\
\hline 001 & 011 & Node 12 \\
\hline 001 & 100 & Node 13 \\
\hline 001 & 101 & Node 14 \\
\hline 001 & 110 & Node 15 \\
\hline 001 & 111 & Node 16 \\
\hline 010 & 000 & Node 17 \\
\hline 010 & 001 & Node 18 \\
\hline 010 & 010 & Node 19 \\
\hline 010 & 011 & Node 20 \\
\hline 010 & 100 & Node 21 \\
\hline 010 & 101 & Node 22 \\
\hline 010 & 110 & Node 23 \\
\hline 010 & 111 & Node 24 \\
\hline 011 & 000 & Node 25 \\
\hline 011 & 001 & Node 26 \\
\hline 011 & 010 & Node 27 \\
\hline 011 & 011 & Node 28 \\
\hline
\end{tabular}

\begin{tabular}{|c|c|c|}
\hline 011 & 100 & Node 29 \\
\hline 011 & 101 & Node 30 \\
\hline 011 & 110 & Node 31 \\
\hline 011 & 111 & Node 32 \\
\hline 100 & 000 & Node 33 \\
\hline 100 & 001 & Node 34 \\
\hline 100 & 010 & Node 35 \\
\hline 100 & 011 & Node 36 \\
\hline 100 & 100 & Node 37 \\
\hline 100 & 101 & Node 38 \\
\hline 100 & 110 & Node 39 \\
\hline 100 & 111 & Node 40 \\
\hline 101 & 000 & Node 41 \\
\hline 101 & 001 & Node 42 \\
\hline 101 & 010 & Node 43 \\
\hline 101 & 011 & Node 44 \\
\hline 101 & 100 & Node 45 \\
\hline 101 & 101 & Node 46 \\
\hline 101 & 110 & Node 47 \\
\hline 101 & 111 & Node 48 \\
\hline 110 & 000 & Node 49 \\
\hline 110 & 001 & Node 50 \\
\hline 110 & 010 & Node 51 \\
\hline 110 & 011 & Node 52 \\
\hline 110 & 100 & Node 53 \\
\hline 110 & 101 & Node 54 \\
\hline 110 & 110 & Node 55 \\
\hline 110 & 111 & Node 56 \\
\hline 111 & 000 & Node 57 \\
\hline 111 & 001 & Node 58 \\
\hline 111 & 010 & Node 59 \\
\hline 111 & 011 & Node 60 \\
\hline 111 & 100 & Node 61 \\
\hline 111 & 101 & Node 62 \\
\hline 111 & 110 & Node 63 \\
\hline 111 & 111 & Node 64 \\
\hline
\end{tabular}

In 3D NOC architecture nodes are configured in X, Y and $\mathrm{Z}$ directions. In $2 \mathrm{D} \mathrm{NoC}$, sometimes there are the chances of not receiving the exact data sent by the sending node [12]. It results into an erroneous transmission. The 3D NoC architecture assures the true data transmission. Figure 2 shows the $8 \times 8 \times 8$ switching mesh network [14]. Functionality of the 3D NOC architecture is described in Table 3. Since it was not possible to identify the nodes in one direction, an alternative approach was adopted to identify the nodes in 3D NoC architecture. 3D topological structure was broke into parallel 2D structures like $\mathrm{XY}$ axis, $\mathrm{YZ}$ axis, $\mathrm{ZX}$ axis. Row address, column address and third address represents the addresses of the nodes in $\mathrm{X}, \mathrm{Y}$ and $\mathrm{Z}$ axis respectively. Parallel Processing and features of pipeline makes the 3D structure faster than 2D structure. This leads to analyze the hardware parameters needed for chip development such as Synthesis Options Summary, VHDL Compilation, VHDL Analysis, Device utilization summary, Timing report, delay time calculation are the core parameters to design the chip. 


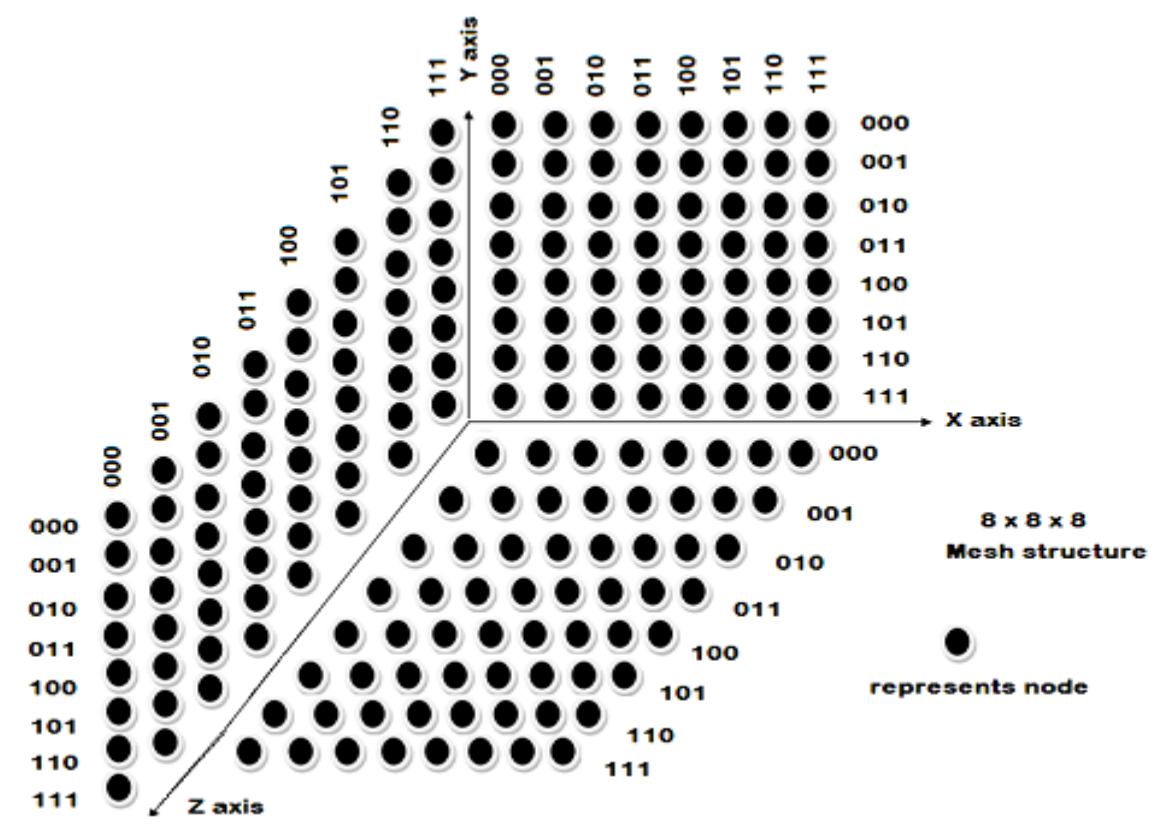

Figure 2 Three dimensional (3D) network structure for $(8 \times 8 \times 8)$ switching cross point

Table 3 Node address generation scheme in 3D network structure

\begin{tabular}{|c|c|c|c|c|c|c|}
\hline \multicolumn{2}{|c|}{ XY Dimensional } & \multicolumn{2}{|c|}{ YZ Dimensional } & \multicolumn{2}{|c|}{ ZX Dimensional } & \multirow{2}{*}{$\begin{array}{l}\text { Destination node } \\
\text { selection }\end{array}$} \\
\hline $\begin{array}{c}\text { Row } \\
\text { address }\end{array}$ & $\begin{array}{l}\text { Column } \\
\text { address }\end{array}$ & $\begin{array}{l}\text { Column } \\
\text { Address }\end{array}$ & $\begin{array}{c}\text { Third } \\
\text { address }\end{array}$ & $\begin{array}{c}\text { Row } \\
\text { address }\end{array}$ & $\begin{array}{c}\text { Third } \\
\text { address }\end{array}$ & \\
\hline 000 & 000 & 000 & 000 & 000 & 000 & Node1 \\
\hline $\begin{array}{c}: \\
000\end{array}$ & $\begin{array}{c}: \\
111 \\
\end{array}$ & $\begin{array}{c}: \\
000\end{array}$ & $\begin{array}{c}: \\
111 \\
\end{array}$ & $\begin{array}{c}: \\
000\end{array}$ & $\begin{array}{c}: \\
111 \\
\end{array}$ & $\begin{array}{c}: \\
\text { Node8 }\end{array}$ \\
\hline 001 & 000 & 001 & 000 & 001 & 000 & Node9 \\
\hline $\begin{array}{c}: \\
001\end{array}$ & $\begin{array}{c}: \\
111\end{array}$ & $\begin{array}{c}: \\
001\end{array}$ & $\begin{array}{c}: \\
111\end{array}$ & $\begin{array}{c}: \\
001\end{array}$ & $\begin{array}{c}: \\
111\end{array}$ & $\begin{array}{c}: \\
\text { Node16 }\end{array}$ \\
\hline 010 & 000 & 010 & 000 & 010 & 000 & Node17 \\
\hline$:$ & $:$ & $:$ & : & : & : & : \\
\hline 010 & 111 & 010 & 111 & 010 & 111 & Node24 \\
\hline 011 & 000 & 011 & 000 & 011 & 000 & Node 25 \\
\hline$:$ & $:$ & $:$ & $:$ & $:$ & $:$ & : \\
\hline 011 & 111 & 011 & 111 & 011 & 111 & Node 32 \\
\hline 100 & 000 & 100 & 000 & 100 & 000 & Node33 \\
\hline$:$ & $:$ & $10 R$ & $:$ & $:$ & $:$ & : \\
\hline 100 & 111 & 100 & 111 & 100 & 111 & Node 40 \\
\hline 101 & 000 & 101 & 000 & 101 & 000 & Node41 \\
\hline : & : & : & : & : & : & : \\
\hline 101 & 111 & 101 & 111 & 101 & 111 & Node 48 \\
\hline 110 & 000 & 110 & 000 & 110 & 000 & Node49 \\
\hline$:$ & $:$ & & $:$ & 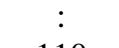 & $:$ & \\
\hline 110 & 111 & 110 & 111 & 110 & 111 & Node 56 \\
\hline 111 & 000 & 111 & 000 & 111 & 000 & Node 57 \\
\hline $\begin{array}{c}: \\
111\end{array}$ & $\begin{array}{c}: \\
111\end{array}$ & $\begin{array}{c}: \\
111\end{array}$ & $\begin{array}{c}: \\
111\end{array}$ & $\begin{array}{c}: \\
111\end{array}$ & $\begin{array}{c}: \\
111\end{array}$ & $\begin{array}{c}: \\
\text { Node64 }\end{array}$ \\
\hline
\end{tabular}


For example realization of the hardware of any NOC architecture is by the sequential statement in HDL, it takes the individual multiplexer for each logic realization, but if the same algorithm is realized by Parallel Processing [9] [22] [25] like using CASE statement or using Finite State machines (FSM), it takes only one multiplexer to realize all the logics. Therefore efficient coding is required to reduce the hardware, delay and power. For the chip implementation of $8 \times 8 \times 83 \mathrm{D} \mathrm{NOC}$, it was not possible to configure for all nodes at one time. Therefore $8 \times 8 \times 8$ network was divided into in $8 \times 82 \mathrm{D}$ NOC in XY direction, $8 \times 8$ 2D NOC in YZ, $8 \times 82 \mathrm{D}$ NOC in $\mathrm{ZX}$ direction. The $8 \times 82 \mathrm{D}$ NOC configuration in $\mathrm{XY}$ direction were assigned 3 bits for row addresses on $\mathrm{X}$ axis and 3 bits for column address on $\mathrm{Y}$ axis. The $8 \times 82 \mathrm{D}$ NOC configuration in $\mathrm{YZ}$ direction were assigned 3 bits for column addresses on $\mathrm{Y}$ axis and 3 bits for third address on $\mathrm{Z}$ axis The 2D NOC configuration $8 \times 8$ in XZ direction were assigned 3 bits for row addresses on $\mathrm{X}$ axis and 3 bits for third address on $\mathrm{Z}$ axis. The address generation scheme of 3D NOC is shown in the table 3 .

As a specific example, let the node no. 64 needs to be identified. The node detection will only be realized the address in $\mathrm{XY}$ direction $(\mathrm{X}=$ Row address (110), $\mathrm{Y}=$ Column address (100)), $\mathrm{YZ}$ direction ( $\mathrm{Y}=$ Column address (110), $\mathrm{Z}=$ Third address (100)) and $Z X$ direction ( $Z=$ Row address (110), $X=$ Third address (100)) will be transmitted.

\section{RESULT \& PERFORMANCE EVALUATON}

The functional simulation of the 3D NOC structure is done with the help of Modelsim $10.1 \mathrm{~b}$ software and all the cases are tested. The snap shot for the same is shown in the figure 4 . The design parameters of 3D NOC are listed in table 4.

Table 4 Design parameters and their functional description

\begin{tabular}{|l|l|}
\hline Parameter & Functional Description \\
\hline reset & $\begin{array}{l}\text { used for synchronization of the } \\
\text { components by using clk }\end{array}$ \\
\hline Clk & To generate to clk pulse \\
\hline Node_address [4:0] & address of destination node \\
\hline row_address [2:0] & $\begin{array}{l}\text { represents the address of the } \\
\text { nodes in } x \text { direction }\end{array}$ \\
\hline column_address [2:0] & $\begin{array}{l}\text { represents the address of the } \\
\text { nodes in y direction. }\end{array}$ \\
\hline Third_address[2:0] & $\begin{array}{l}\text { represents the address of the } \\
\text { nodes in z direction. }\end{array}$ \\
\hline read_en & control signals (read operation) \\
\hline write_en & control signals (write operation) \\
\hline encrypted_data_in[7:0] & represents input data of 8 bits \\
\hline decrypted_data_out[7:0] & $\begin{array}{l}\text { presents the output data of } 8 \text { bits } \\
\text { for the destination node. }\end{array}$ \\
\hline cipher_text [7:0] & $\begin{array}{l}\text { presents the output data of } 8 \text { bits } \\
\text { after encryption and input to } \\
\text { decryption logic. }\end{array}$ \\
\hline \multicolumn{1}{|c|}{$\mathrm{n}$} & $\begin{array}{l}\text { data width of data, block size, } \\
\text { integer }\end{array}$ \\
\hline $\mathrm{k}$ & Key size integer type \\
\hline
\end{tabular}

\subsection{Simulation Process sequence}

Step 1: reset $=1$, clk is used for synchronization and then run. Step 2: reset $=0$, same clk was used for synchronization. Step 3: Select the address of destination node Node_address. Step 4: Force the value of row_address and column_address of destination node.
Step 5: Select the value of block size $\mathrm{n}$ and key size $\mathrm{k}$ Step 6: Give the eight bit value of data_in. Force write_en $=1$ and read_en $=0$ and then run.

Step76: write_en $=0$ and read_en $=1$ and run.Desired output on destination is achieved.

When write_en $=1$ and read_en $=0$, the data is written in temp variables of TACIT logics from the source node in encryption algorithm, when write_en $=0$ and read_en $=1$, the data is read from the temp variable of TACIT logics to destination node in decryption logic. Clk is applied at the positive edge clock pulse and reset is kept at 1 for the initial state, When reset $=0$ the data is transmitted by encrypted_data_in [7:0]. The data length encrypted_data_in [7:0] and key size $\mathrm{k}$ is not constant, it can vary according to the requirement and application.

Figure 4 shows the simulated result for $8 \times 8 \times 8$ 3D $\mathrm{NoC}$ architecture. The coding for the implementation is done is the VHDL. The design parameters are similar to the 2D design with additional parameter for third address. Third address [2:0] represents the address of the nodes in $\mathrm{z}$ direction.

\subsection{Device Utilization for 3D NOC}

Device utilization report gives the percentage utilization [13] of device hardware for the chip implementation. Device hardware includes, logic gates, buffers, multiplexer, decoders, latches, flip flops etc. Register transfer Logic (RTL) is shown in the figure 3. Synthesis report shows the complete details of device utilization.

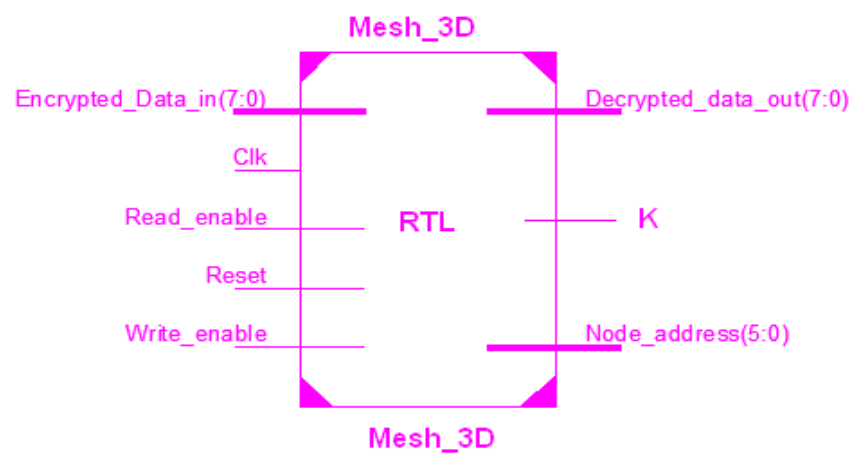

Figure 3 Xilinx RTL view of 3D NOC with TACIT Logic

Selected Device: xc3s50-5-tq144, this device is targeted for FPGA

Table 5 Device utilization in 3D structure

\begin{tabular}{|l|lll|}
\hline Device part & Utilization & \\
\hline Number of Slices & 10 out of & 768 & $1 \%$ \\
Number of Slice Flip Flops & 16 out of & 1536 & $1 \%$ \\
Number of 4 input LUTs & 18 out of & 1536 & $1 \%$ \\
Number of bonded IOBs & 25 out of & 97 & $25 \%$ \\
Number of GCLKs & 2 out of & 8 & $25 \%$ \\
\hline
\end{tabular}

\subsection{Timing Summary}

Timing [13] details provides the information of delay, minimum period, minimum input arrival time before clock and maximum output required time after clock

Speed Grade: -5

Minimum period: 2.010ns (Maximum Frequency: 497.401MHz)

Minimum input arrival time before clock: $5.354 \mathrm{~ns}$

Maximum output required time after clock: $6.205 \mathrm{~ns}$

Total memory usage is 151948 kilobytes 


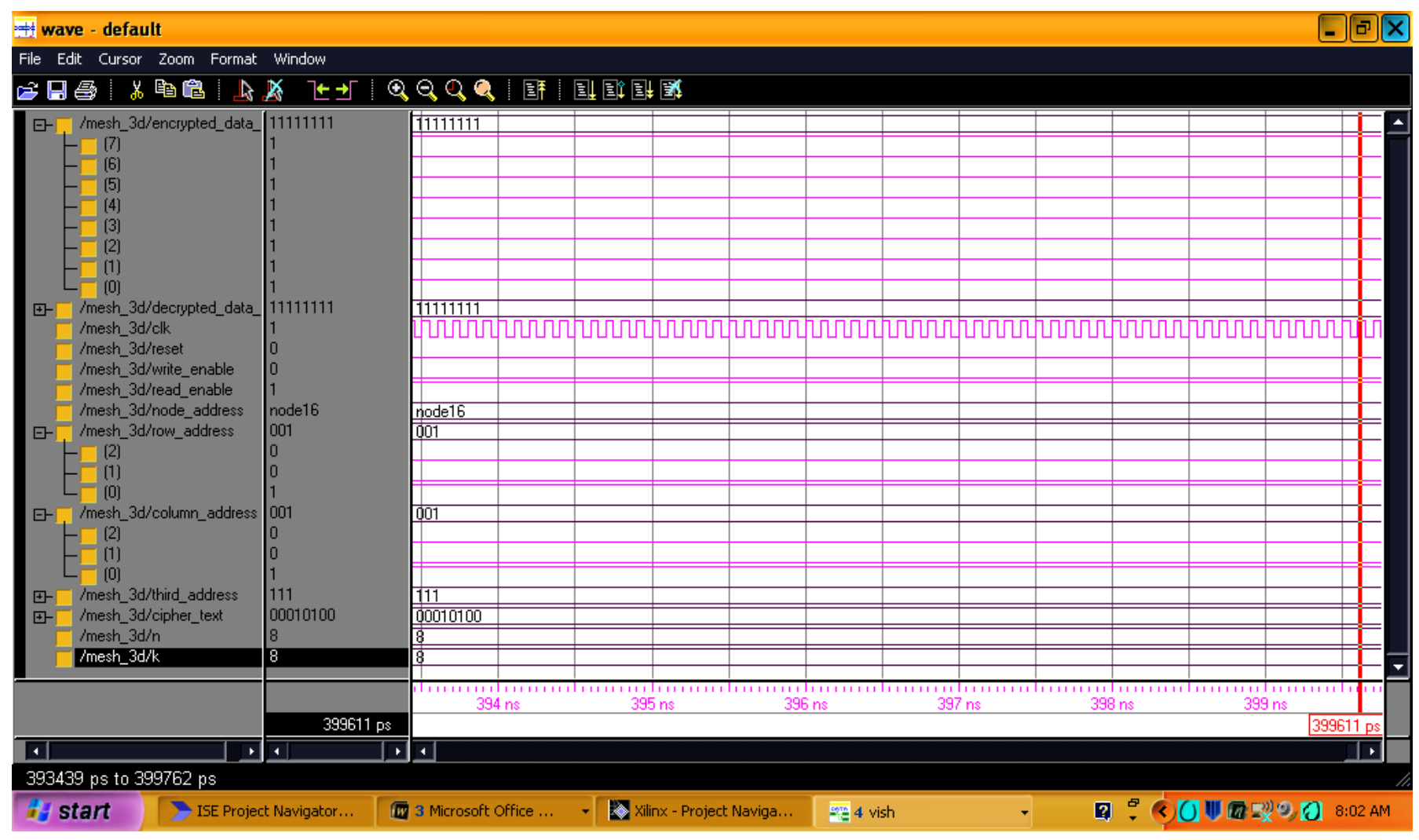

Figure 4 Modelsim output of 3D Mesh Topological Structure $(8 \times 8 \times 8)$

\section{CONCLUSION}

Hardware implementation of the 3D topological mesh topology was carried out with TACIT Encryption and decryption algorithm. The major advantage of the programmable structure is to identify and replacement of the faulty node. In the network structure, stored program techniques are used. If the implementation of the entire structure is done by programmable switches and ICs, then the complexity of the system is reduced. Reprogramming NOC helps to identity the faulty node in the network structure. 3D NoC architecture was found more efficient for long data transfer. Since the signal can get any axis $\mathrm{XY}, \mathrm{YZ}$ or ZX. There are very rare chances of signal being lost. 2D NoC architecture was found suitable for small area communication or LAN network but not in large area network. In the continuation of this work, a study can be carried out by taking into account the larger number of nodes.

\section{REFERENCES}

[1] W. Wolf, The future of multiprocessor systems-on-chips, in: Proceedings of the $41^{\text {st }}$ Design Automation Conference (DAC'04), June2004, pp. 681-685.

[2] Manmeet Kaur, Manjit Kaur,Gurmohan Singh, C-DAC Mohali India, Comparison of TACIT Encryption Algorithm with Various Encryption Algorithms, International Journal of Electronics and Computer Science Engineering, page (1-10)

[3] Jason Cong, Yuhui Huang, and Bo Yuan Computer Science Department University of California, Los Angeles Los Angeles, USA, 978-1-4577-1400-9/11/\$26.00 @2011 IEEE, A Tree-Based Topology Synthesis for On-Chip Network ,pp 2-6
[4] Naveen Chaudhary, Bursty Communication Performance Analysis of Network-on-Chip with Diverse Traffic Permutations International Journal of Soft Computing and Engineering (IJSCE) ISSN: 2231-2307, Volume-1, Issue6, January 2012, (page 1)

[5] Mohammad Ayoub Khan, Abdul Quaiyum Ansari, A Quadrant-XYZ Routing Algorithm for 3-D Asymmetric Torus Network-on-Chip, The Research Bulletin of Jordan ACM, ISSN: 2078-7952, Volume II (II) pp(18-26)

[6] L. Benini, G. De Micheli, Networks on chip: a new SoC paradigm, IEEE Comput. 35(1) (2002) 70-78.

[7] W. J. Dally, B. Towles, Route packets not wires: on-chip interconnection networks, in: Proceedings of Design Automation Conference (DAC'01), ACM, IEEE Press, New York, June 2001, pp. 648-689.

[8] F. Angiolini, P. Meloni, S. Carta, L. Benini, L.Raffo, Contrasting a NoC and a traditional interconnect fabric with layout awareness, in: Proceedings of Design, Automation and Test in Europe Conference and Exhibition (DATE'06), Munich, Germany, ACM, IEEE Press, NewYork, 2006,pp.124-129.

[9] Adesh Kumar, Arpit Jain, Rajeev Kumar, SMART Conference Proceedings, "Network On Chip Implementation Of 2D Mesh Topological Structure In HDL Environment, (page 1-6)

[10 ]A Network on Chip Architecture and Design Methodology Laboratory of Electronics and Computer Systems, Department of Microelectronics and Information Technology, Royal Institute of Technology, Kista, 
Stockholm, Sweden VTT Electronics, Box 1100, Oulu, FIN-90571, Finland

[11] S. Borkar, Idesign challenges of technology scaling." IEEE Micro, no.4, p. 2329, July-August 1999.

[12] Xin Wang and Jari Nurmi,Comparison of a Ring On-Chip Network and a Code-Division Multiple-Access On-Chip Network, Hindawi Publishing Corporation VLSI Design Volume2007,ArticleID 18372, 14 page

[13] Semiconductor Complex Limited, Internet PDF: Data sheets of XC 95 series CPLD [Online]. Available: http://sclindia.com,

[14] K. Asanovi, R. Bodik, B. Catanzaro, J. Gebis, P. Husbands, K. Keutzer, D .Patterson, W. Plishker, J. Shalf, S. Williams, and K. Yelick, IThe landscape of parallel computing research : A view from berkeley," University of California at Berkeley, December 2006. [Online]. Available: http: // parlab. eecs. berkeley. edu/ pubs/ EECS- 2006-183 .pdf

[15] S. Borkar, Idesign challenges of technology scaling." IEEE Micro, no.4, p. 2329, July-August 1999.

[16] Vitorde Paulo and Cristinel Ababei, 3D Network-on Chip Architectures Using Homogeneous Meshes and Heterogeneous Floorplans, Hindawi Publishing Corporation International Journal of Reconfigurable Computing Volume 2010, Article ID603059, 12 pages

[17] M.Coppola, S.Curaba, M.Grammatikakis, R.Locatelli, G.Maruccia, F.Papariello, L.Pieralisi, White paper on OCCN: A Network-On-Chip Modeling and Simulation Framework, ISD Integrated system developments, page 8
[18] Davide Bertozzi and Luca Benini, A Network-on-Chip Architecture for Gigascale Systems-on-Chip, IEEE Circuits and systems magazine, second quarter 2004, Xpipes, page (2-6)

[19] J. D. Owens, W. J. Dally etal., "Research challenges for on-chip inter connection networks," IEEE MICRO, vol.27, no.5, pp.96-108,Oct.2007.

[20] A. Jantschand H.Tenhunen, Networks on chip. Kluwer Academic publishers, 2003

[21] T .Bjerregaard and S .Mahadevan,"A survey of research and practices of network-on-chip," ACM Comp. Surveys, vol.38, no.1,pp.1-51,Mar.2006.

[22] Rikard Thid Thesis on "A Network on Chip Simulator", Sweden Master of Science Thesis in Electronic System Design, Royal Institute of Technology Aug 2002, Page (927)

[23] Prosanta Gope, Ajit Singh, Nikhil Pawha, Ashwani Sharma, An Efficient Cryptographic Approach for Secure Policy Based Routing (TACIT Encryption Technique), 978-1-4244-8679-3/11/@2011 IEEE Page (1-4)

[24] Wen-Chung Tsai,, Ying- Cherng Lan,, Yu-Hen Hu, and Sao-Jie Chen Review Article " Networks on Chips : Structure and Design Methodologies" Hindawi Publishing Corporation Journal of Electrical and Computer Engineering Volume 2012, Article ID 509465, 15 page

[25] P. Pratim Pande, C. Grecu, M. Jones, A. Ivanov, and R. Saleh, "Performance evaluation and design trade-offs for network-on-chip interconnect architectures", IEEE Transactions on Computers, vol. 54, no. 8, pp. 1025 1040, 2005. 